\title{
Test Plan for Single Well Injection/Extraction Characterization of DNAPL (U)
}

by

K. Jerome

Westinghouse Savannah River Company

Savannah River Site

Aiken, South Carolina 29808

DOE Contract No. DE-AC09-89SR18035

This paper was prepared in connection with work done under the above contract number with the U.S. Department of Energy. By acceptance of this paper, the publisher and/or recipient acknowledges the U.S. Government's right to retain a no:'iexclusive, royalty-free license in and to any copyright covering this paper, along with the right to reproduco and to authorize others to reproduce all or part of the copyrighted paper. 


\section{DISCLATMER}

This report was prepared as an account of work sponsored by an agency of. the United States Government. Neither the United States Government nor any agency thereof, nor any of their employees, makes any warranty, express or implied, or assumes any legal liability or responsibility for the accuracy, completeness, or usefulness of any information, apparatus, product, or process disclosed, or represents that its use would not infringe privately owned rights. Reference herein to any specific commercial product, process, or service by trade name, trademark, manufacturer, or otherwise does not necessarily constitute or imply its endorsement, recommendation, or favoring by the United States Government or any agency thereof. The views and opinions of authors expressed herein do not necessarily state or reflect those of the United States Government or any agency thereof.

This report has been reproduced directly from the best available copy.

Available to DOE and DOE contractors from the Office of Scientific and Technical Information, P.O. Box 62, Oak Ridge, TN 37831; prices available from (615) 57.6-8401.

Available to the public from the National Technical-Information Service, U.S. Department of Commerce, 5285 Port Royal Road, Springfield, VA 22161. 


\title{
Test Plan
}

\author{
- for \\ Single Well \\ Injection/Extraction Characterization
}

of

DNAPL

U. S. Department of Energy Office of Technology Development

U.S. Department of Energy Savannah River Operations

Prepared by:

technical personnel at the Savannah River Site

U. S. Department of Energy

Westinghouse Savannah River Company

Savannah River Technology Center

Savannah River Site

Aiken, SC 29808

operated by:

Westinghouse Savannah River Company

for the U. S. Department of Energy under Contract No. DE-AC09-89SR18035

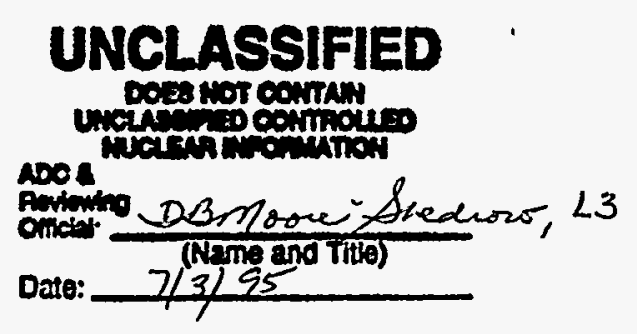




\section{Test Plan}

$$
\text { for }
$$

\section{Single Well \\ Injection/Extraction Characterization}

of

\section{DNAPL}

U. S. Department of Energy Office of Technology Development

U.S. Department of Energy Savannah River Operations

Prepared by:

B. B. Looney

K. M. Jerome

S. Burdick

J. Rossabi

T. R. Jarosch

C. A. Eddy-Dilek

U. S. Department of Energy

Westinghouse Savannah River Company

Savannah River Technology Center

Savannah River Site

Aiken, SC 29808

operated by:

Westinghouse Savannah River Company

for the U. S. Department of Energy under Contract No. DE-AC09-89SR18035 


\section{TABLE OF CONTENTS}

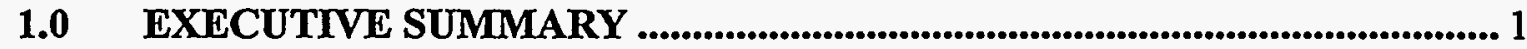

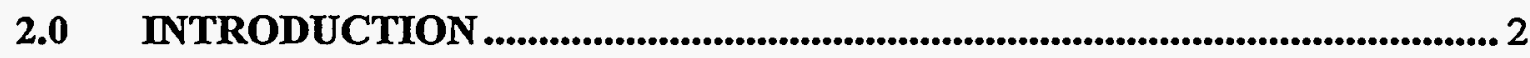

3.0 BACKGROUND .............................................................................................. 2

4.0 SUMMARY DESCRIPTION OF PROPOSED TEST $\ldots \ldots \ldots \ldots \ldots \ldots \ldots \ldots \ldots \ldots \ldots \ldots \ldots \ldots \ldots \ldots$

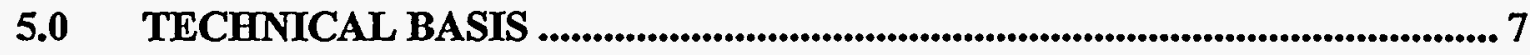

5.1 Volumes Selected ............................................................................................. 7

5.2 Selection of Solubilizing Alcohol .............................................................. 13

5.3 Selection of Solubilizing Alcohol Concentration ............................................... 15

5.4 Selection of Wells ......................................................................................................... 16

5.5 Selection of Tracers ........................................................................................ 19

5.6 Tracer Tests .............................................................................................. 19

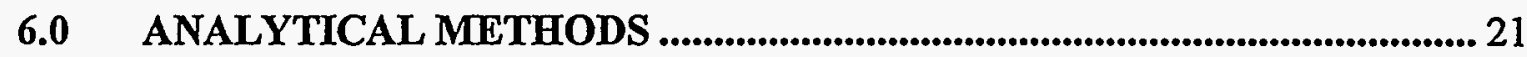

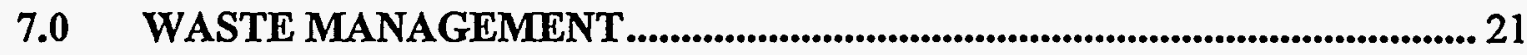

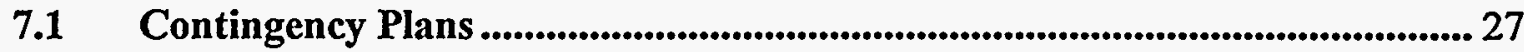

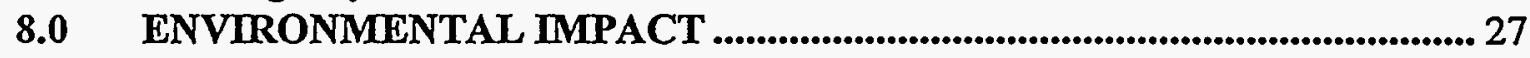

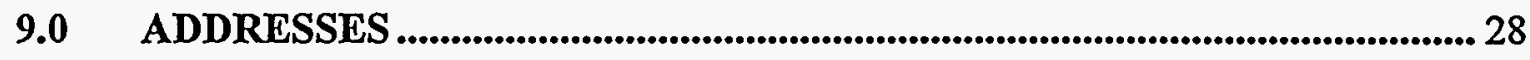

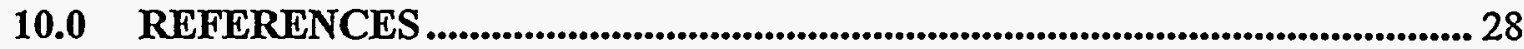




\section{LIST OF TABLES}

Table 4.1 Summary Table of Operating Parameters for Injection/Extraction Test.......... 9

Table 5.1 Radius of Infiltration of Injection Fluid for a 4" dia. Well as a Function of Equipment Volumes and Injection Volumes .................................... 11

Table 6.1 Analytical Methods ...................................................................... 23 


\section{LIST OF FIGURES}

Figure 3.1 Area Map of the Test Site, Located Adjacent to the M-Area Hazardous Waste Management Facility

Figure 3.2 Map of Wells Identified for the Injection/Extraction Test............................. 6

Figure 4.1 Representation of Test Equipment Inside the Test Wells and Depth of Penetration of the Injection Fluid into the Geologic Formation. 8

Figure 5.1 Radius of Infiltration of Injection Fluid for a 4" dia. Well........................... 12

Figure 5.2 Ternary Phase Diagram for Alcohol-Water-DNAPL System....................... 14

Figure 5.3 Comparison of PCE Solubility as a Function of Cosolvent Concentration.. 17

Figure 5.4 DNAPL Interfacial Tension as a Function of Alcohol Concentration.......... 18

Figure 5.5 Projected Behavior of Small Scale Injection/Extraction Test (DNAPL Characterization)

Figure 5.6 Theoretical Behavior of Small Scale Injection/Extraction Test (DNAPL Characterization) 22

Figure 7.1 Schematic Diagram of Effluent Streams from Treatment Unit for the Well Water from the Injection/Extraction Test. 


\section{List of Attachments}

Attachment A Estimate of Volume of TSCA Waste Generated

29

Attachment B Calculation of Amount of PCBs Present in 500 gallons of TSCA Waste (DNAPL containing PCBs) 


\subsection{EXECUTTVE SUMMARY}

Soils and groundwater beneath an abandoned process sewer line in the A/M Area of the Savannah River Site (SRS) contain elevated levels of volatile organic compounds, specifically trichloroethylene (TCE) and tetrachloroethylene (PCE), two common chlorinated solvents. These compounds have low aqueous solubilities, thus when released to the subsurface in sufficient quantity, tend to exist as immiscible fluids or nonaqueous phase liquids (NAPLs). Because chlorinated solvents are also denser than water, they are referred to by the acronym DNAPLs, or dense non aqueous phase liquids. Technologies targeted at the efficient characterization or removal of DNAPL are not currently proven. For example, most DNAPL studies rely on traditional soil and water sampling and the fortuitous observation of immiscible solvent. Once DNAPL is identified, soil excavation (which is only applicable to small contained spill sites) is the only "proven" cleanup method. New cleanup approaches based on enhanced removal by surfactants and/or alcohols have been proposed and tested at the pilot scale. As described below, carefully designed experiments similar to the enhanced removal methods may provide important characterization information on DNAPLs

The first step in a targeted DNAPL program is the careful identification of the nature and location of DNAPL in the soil and groundwater. Savannah River Site completed a preliminary (Phase I) DNAPL characterization program that provides initial information about the DNAPL in the vicinity of the M-Area Settling Basin and other nearby sources. Additional characterization activities, based on the Phase I data, will provide further information and confirmation of the initial results. Use of the Phase I study to focus current and future DNAPL activities results in a relatively cost effective program.

One promising method of accelerating the removal of residual DNAPLs from aquifers involves the solubilization and/or mobilization of trapped globules by alcohol-water solutions. This technology was originally developed in the petroleum industry for the recovery of residual oil after waterflooding. We propose the use of injection and extraction of alcohol solutions as a characterization tool rather than a remediation tool.

For the injection/extraction tests small amounts of solubilizing solution will be used to identify the presence or absence of DNAPL in the immediate vicinity of existing monitoring wells. Short tests will be performed at each suspect well and several control wells. In each test, a small volume of solubilizing solution is injected, followed by a shut in period (equilibration period), and then extraction of a larger volume of water from the formation (to assure complete recovery of the amendments). Two tests, or stages, will be performed at each well. In the first stage, water will serve as the solubilizing solution, and in the second stage, alcohol solution will be used. The presence of DNAPL will cause clear differences between the stages. The proposed small scale use of alcohols initially as a characterization tool, rather than as a remediation tool, has several advantages: 
1) Existing monitoring wells are used minimizing additional drilling and intrusion into the contaminated site, and 2) the results will provide unequivocal data on the presence or absence of DNAPL in the vicinity of the suspect wells. Presence of DNAPL will be indicated by a difference in concentration of DNAPL present in the alcohol stage of the test from that present in the water stage of the test. Thus the test will provide key information supporting decision making and may provide the basis for modeling and design of future DNAPL remediations based on solubilization by alcohols. Specific details of the test are addressed below.

\subsection{INTRODUCTION}

In continuing our support to the $\mathrm{A} / \mathrm{M}$-Area groundwater corrective action, we are proposing to identify the nature and location of DNAPL in the subsurface near the MArea Settling Basin and other sources. A small scale injection/extraction test is proposed as a part of the expanded characterization activities.

\subsection{BACKGROUND}

The M-Area of Savannah River Site was a fuel and target fabrication facility. The mission of this area was processing uranium, lithium and other materials into fuel elements and targets for use in the nuclear production reactors. The processes were primarily metallurgical and mechanical, such as casting, extrusion, plating, hot-die-sizing, welding and magneforming. Solvent cleaning and acid/caustic etching were used to prepare the materials.

The M-Area Settling Basin and associated areas (the overflow ditch, Lost Lake, the seepage area, and the inlet process sewer line) have been designated as the M-Area Hazardous Waste Management Facility. This facility received process effluent from 1958 until 1985. VOC contamination of soils and groundwater occurred in M-Area as a result of breaks in the old process-sewer line and disposal to the basin. Other sources in $\mathrm{A} / \mathrm{M}$ Area include the A-014 Outfall, the solvent storage tank, and surface discharges from the Savannah River Technical Center.

The M-Area Settling Basin Hazardous Waste Management Facility has been capped and closed under RCRA and is a certified closure as a landfill. The work being proposed is intended to support the $\mathrm{A} / \mathrm{M}$ Area groundwater corrective action.

There have been a wide range of research and development activities that have been performed in support of the A/M -Area groundwater corrective action. These various activities have been designated the Integrated Demonstration and include use of horizontal wells for remediation, an in situ air stripping test, in situ bioremediation test, off gas treatment technology tests, a radio frequency heating test, and an ohmic heating test.

Characterization of DNAPL above and below the water table is an important component 
of developing a comprehensive remediation system. Characterization of DNAPL below the water table is often difficult, due to DNAPL's dispersed occurence and complex behavior. Above the water table, residual DNAPL will reside in intergranular pores, held by capillary forces. The overall characterization of subsurface DNAPL distribution requires application of specifically focused characterization technologies based on contaminant attributes and hydrogeological setting. To minimize the potential for DNAPL spreading, noninvasive or minimally invasive technologies should be employed.

Several technologies were used during the earlier Phase I DNAPL characterization. These included: (1) physical and chemical measurements in existing monitoring wells (e.g., interface probe and bailer samples, and visual examination), (2) cone penetrometer to provide detailed data on the geology (clay layers and lithologic controls), and (3) geophysical logging of existing monitoring wells to examine the well casing and formation outside the well casing for indications of DNAPL. Historical data were used to focus the study on the most promising wells and techniques.

A separate phase was identified in monitoring wells MSB-3D and MSB-22 sumps. Both identifications were made based on direct observation of a bottom filling bailer. The dense phases collected from these two wells were sampled and analyzed at different times to allow testing of various hypotheses for DNAPL occurrence. The observed changes in the volume and composition of the dense phase collected from the two sumps at separate times were specifically related to possible DNAPL behavior scenarios. The data suggest that DNAPL has reached the water table only at the largest volume release areas, the MArea Settling Basin (Settling Basin) and the A-014 Outfall. The relatively thick vadose zone beneath A/M-Area tends to limit the downward flux of DNAPL and capture some DNAPL in layered clays. As expected, DNAPL below the water table has been observed where solvent release exceeded the capacity of the vadose zone to moderate the flux of the pure phase to the groundwater. The clearest evidence of DNAPL below the water table was found at the Settling Basin, where a separate phase was identified in the sumps of two wells. The data collected at separate times suggest that the DNAPL below the water table occurs as relatively diffuse ganglia and/or a thin layer on the top of aquitards, and that DNAPL collects in well sumps as a result of dynamic processes. One such process is the accumulation of dense ganglias in the well sump as the well is actively purged and sampled (similar to the accumulation of sediments in the sump).

The cone penetrometer allowed refinement of the delineation of an important clay zone (the"green clay") beneath the water table. Undulations and other structural variations on top of this layer would serve to control the movement of a dense phase below the water table. Based on the cone penetromer results, structure controlled pathways for densitydominated transport below the water table were discerned. Two potential pathways were identified. The primary potential pathway of contaminant migration begins near the Settling Basin, where DNAPL was found in monitoring wells MSB-3D and MSB-22, Figure 3.1. The contour grades toward the west and then north toward MSB-76, where high dissolved constituent concentrations $(>1000 \mathrm{ug} / \mathrm{L}$ ) are reported. Areas along the low 


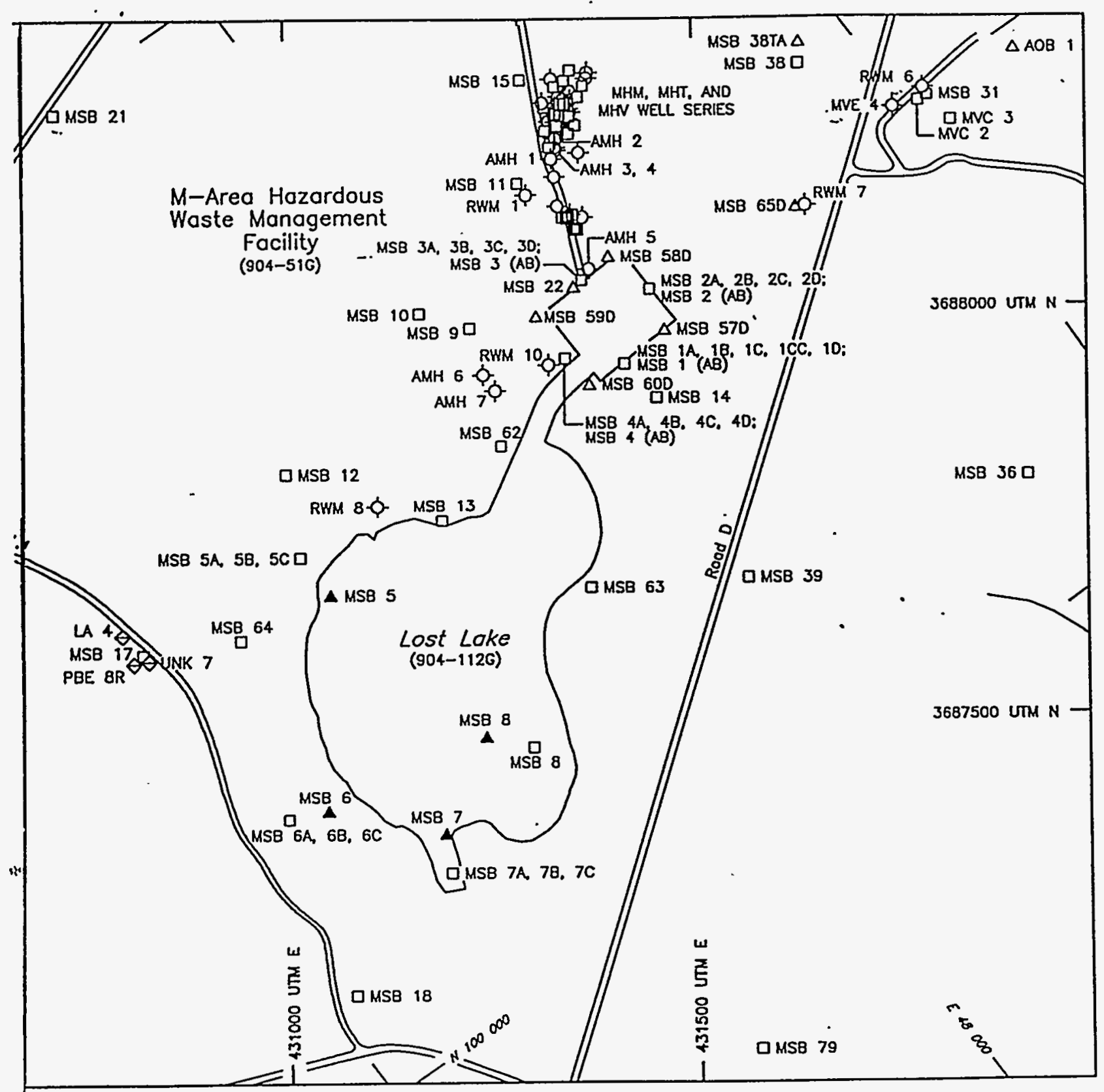

Figure 3.1 Area Map of the Test Site, Located Adjacent to the M-Area Hazardous Waste Management Facility 
points of the path described in this interpretation will be locations of future DNAPL investigation. The geophysical logging data indicate the physical integrity of the PVC monitoring well casings in $\mathrm{A} / \mathrm{M}$-Area have not been substantially impacted by exposure to chlorinated solvents. The wells, even immediately adjacent to the highest volume release areas, do not show signs of mechanical instability, leakage, or other types of large scale failure. Data from a few monitoring wells, however, provide subtle indications of potential exposure to DNAPL. The most consistent DNAPL indications are provided in monitoring wells MSB-9A and MSB-22, with less probable indications from monitoring wells MSB-10A and MSB-11A.

Phase I of the DNAPL characterization provided significant insight into the nature and location of DNAPL in the SRS subsurface. In particular, the data indicate a substantial amount of DNAPL has been trapped in clays and silts in the vadose zone above the water table. The DNAPL present is composed of approximately $95 \%$ TCE and $5 \%$ PCE. Remediation of this material by soil vapor extraction (SVE) before it reaches the water table represents the first major DNAPL-targeted remediation technology. SVE demonstrations have been performed in the $\mathrm{A} / \mathrm{M}$-Area using both horizontal and vertical wells. A full scale SVE design, installed as a component of the A/M-Area groundwater corrective action program is underway, and additional remediation technology demonstrations are planned. Phase I characterization data also suggest that DNAPL below the water table in $\mathrm{A} / \mathrm{M}$-Area is present as disconnected ganglia, rather than as a large, solvent-saturated layer. The objectives of Phase 2 of the DNAPL characterization will focus on: (1) refining our knowledge of the location and nature of DNAPL in the subsurface, and (2) implementing studies to examine the efficacy of potential remediation techniques for DNAPL below the water table. As in Phase 1, non-invasive, or minimally invasive, techniques will be stressed.

The injection/extraction test proposed is an important element of the Phase 2 characterization activities. This characterization test involves the injection/extraction of alcohols or surfactants into existing wells (minimizing cost and eliminating the disruptions associated with drilling activities). It will be conducted within one quarter mile of the MArea Settling Basin Hazardous Waste Management Facility. Figure 3.1 shows the locations of the proposed test wells, the area of review, all monitoring wells, surface bodies of water, roads, and other cultural features. Figure 3.2 shows existing monitoring wells identified for this test. Due to the diffuse nature of the DNAPL occurance below the water table, the injection/extraction test is the the most promising approach for unambiguous indication of the presence or absence of DNAPL near monitoring wells.

\subsection{SUMMARY DESCRTPTION OF PROPOSED TEST}

The proposed test wells were chosen based on previous data of highest concentrations and selected lower concentration control wells. A series of short tests where a small volume of fluid is injected, followed by a shut in (equilibration) period, followed by overextraction is planned. Each test will consist of two stages. The initial stage of each test will involve 


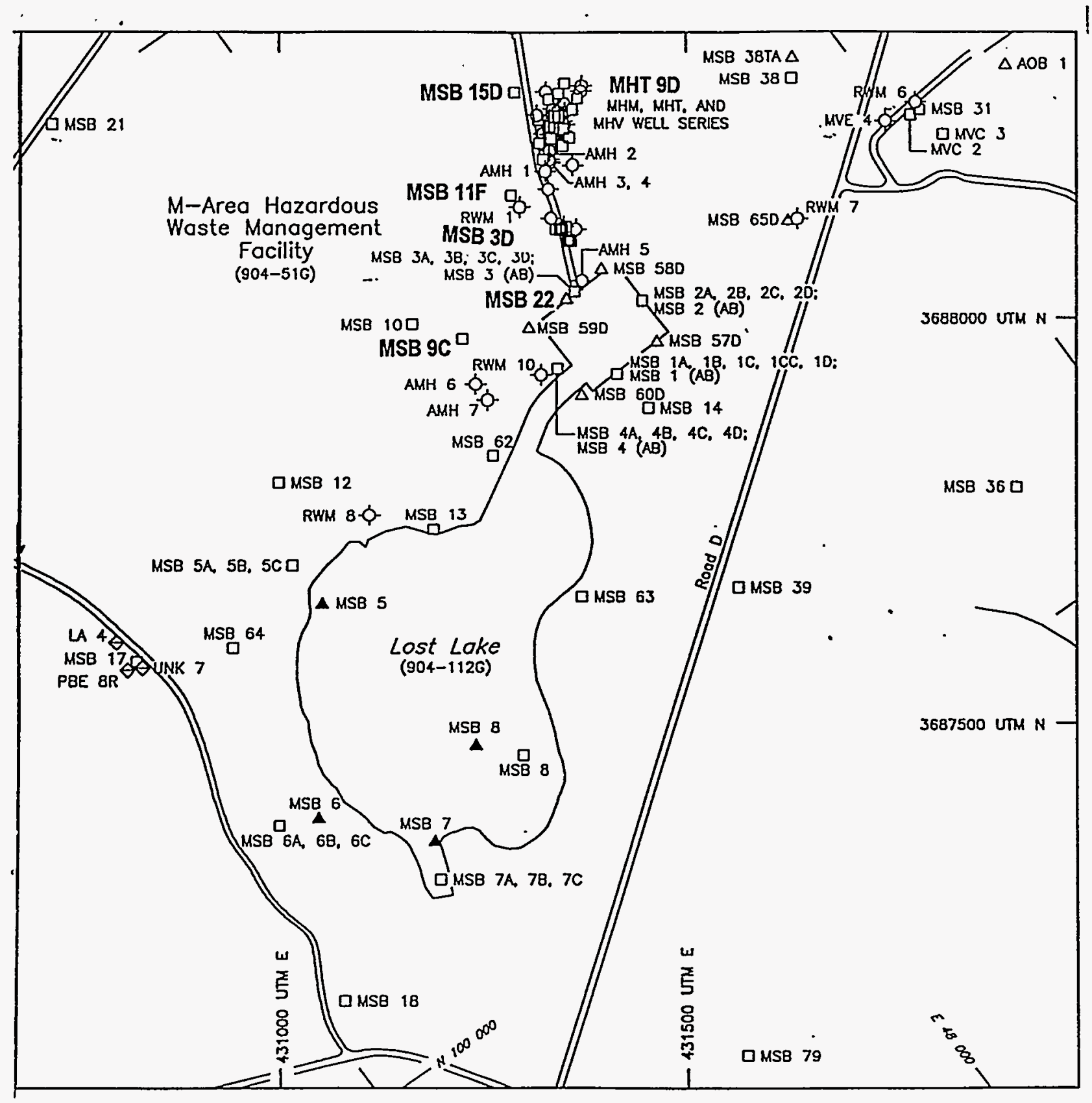

Test wells are identified in bold text.

Figure 3.2 Map of Wells Identified for the Injection/Extraction Test 
the injection, shut in, and overextraction of a known volume of water. This will be followed by a second stage of injection, shut in, and overextraction of a known volume of a solubilizing alcohol solution (e.g., $25 \%$ ethanol). All stages will be run in the batch mode. Presence of DNAPL will be indicated by a difference in the concentration of DNAPL between the two stages of the test. During the program, we will review the potential applicability of other solubilizing agents (e.g., surfactants). If a particularly promising amendment is identified, a permit modification will be prepared for review and approval. Metering pumps will provide an accurate account of all injection volumes. A standard hydrogeology tracer (bromide) will be added to the injected fluid to allow explicit determination of the water mass balance.

The target zone of influence is to be approximately $4-7$ inches into the natural formation around the periphery of each well. Isolation of the screened zone will be accomplished through use of double packers. Figure 4.1 shows the orientation of packers in isolating the test zone. Equipment will be designed to minimize dead volume of the wells, thus reducing both volumes required to reach the natural formation and total volumes removed and managed for waste disposal.

Fluids will be removed utilizing bottom filling lift pumps equipped to carefully monitor extracted volumes. It is proposed that extracted volumes exceed injected volumes by a factor of three, thus assuring complete recovery of amendments. Extracted fluids will be sampled and analyzed for TCE and PCE concentrations, alcohol concentrations, and tracer concentrations. Non aqueous phase liquids will be collected and disposed of as hazardous waste (RCRA F001 and TSCA, as appropriate). Water generated during the test will be collected and disposed of as "investigation derived waste" from the A/M-Area RCRA groundwater corrective action, using an innovative treatment method (oleofilter) followed by a carbon bed followed by the existing wastewater treatment facility (air stripper). Water generated during testing will be carefully monitored and controlled to assure no adverse impact on air stripper performance. Additional analysis will be performed to detect PCB concentrations, as previous sampling activities have indicated the presence of low concentrations of PCB's in the DNAPL phase at the proposed test wells.

A summary of the proposed test wells, solution volumes and other details of the study are provided in Table 4.1.

\subsection{TECHNICAL BASIS}

\subsection{Volumes Selected}

Injection and extraction volumes were chosen based upon our objective to "probe" approximately three inches into the natural formation immediately adjacent to the well screen. Rates will be in the gallons per hour range to minimize hydraulic effects and allow proper mass transfer for solubilization. To calculate necessary volumes, we developed a simplified approach based on propagation of the injected fluid as a cylinder 


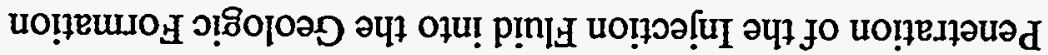

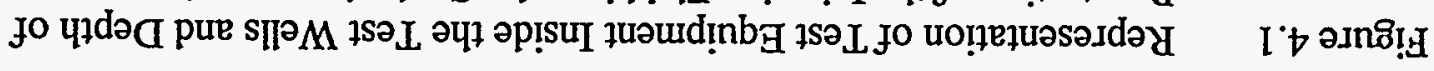

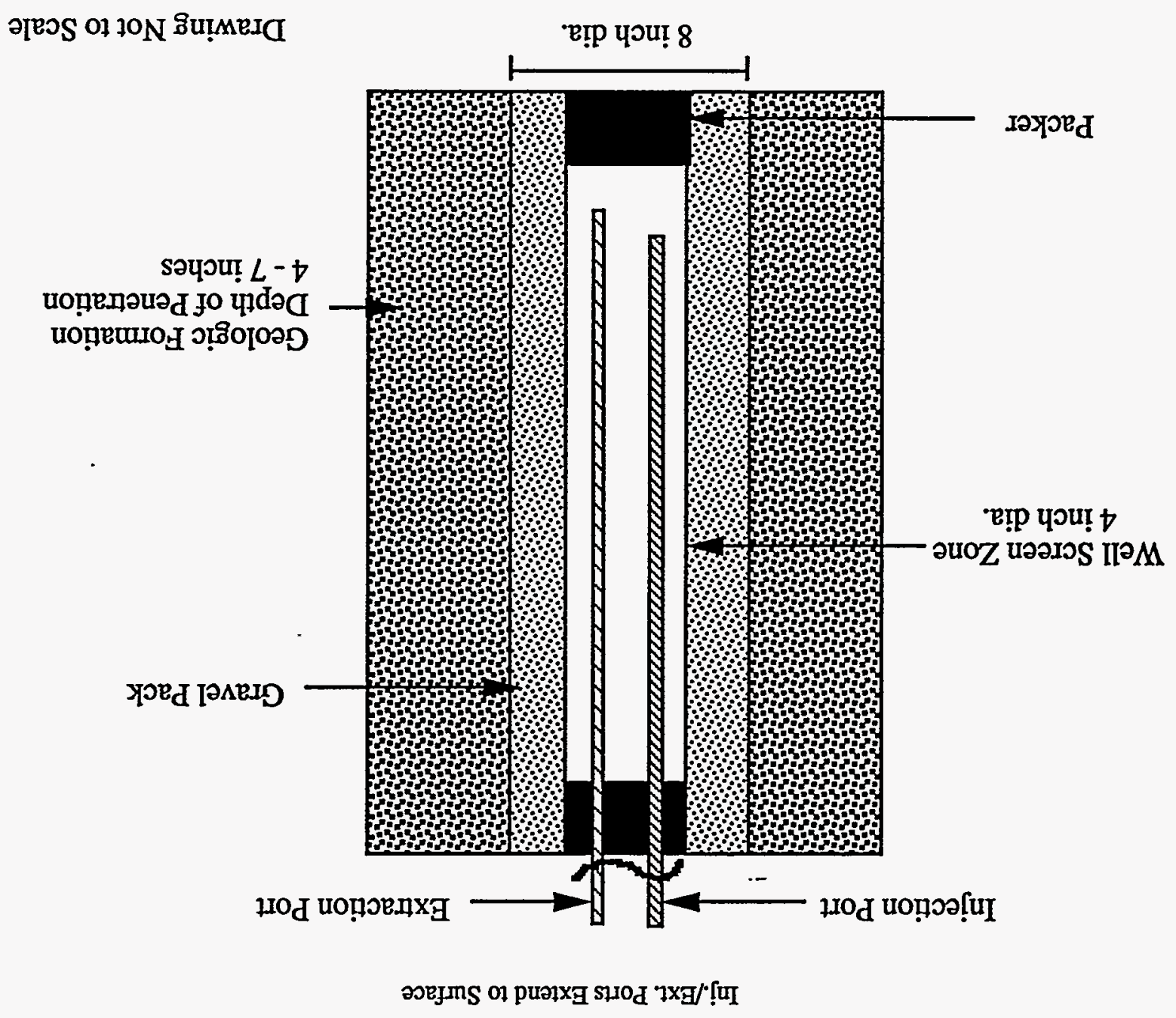


Table 4.1 Summary Table of Operating Parameters for Injection/Extraction Test

\begin{tabular}{|c|c|c|c|}
\hline Test Wells & $\begin{array}{l}\text { Confirmed NAPL } \\
\text { Wells } \\
\text { Suspect NAPL } \\
\text { Wells } \\
\text { Control Wells }\end{array}$ & $\begin{array}{l}\text { Concentrations }>200 \mathrm{ppm} \\
\text { PCE ( } 100 \% \text { of solubility) } \\
\text { and visual identification of } \\
\text { NAPL } \\
\text { Concentrations }>20 \mathrm{ppm} \\
\text { PCE } \\
\text { Concentration }<2 \mathrm{ppm} \mathrm{PCE} \\
\text { ( } 1 \% \text { of solubility) }\end{array}$ & $\begin{array}{l}\text { MSB11F, MSB15D, } \\
\text { MSB9C } \\
\text { MHT9D }\end{array}$ \\
\hline Solution Volumes & $\begin{array}{l}\text { Injection } \\
\text { Extraction } \\
\text { Post-Extraction }\end{array}$ & $\begin{array}{l}\text { water } \\
\text { alcohol solution } \\
\text { water w/groundwater } \\
\text { alcohol solution } \\
\text { w/groundwater } \\
\text { Sudan IV/extracted } \\
\text { groundwater }\end{array}$ & $\begin{array}{l}50 \text { gallons } \\
50 \text { gallons at alcohol conc. } \\
\text { of } 25 \% \text { by vol. and } \\
\text { bromide conc. of } 100 \mathrm{mg} / \mathrm{L} \\
150 \text { gallons } \\
150 \text { gallons } \\
\text { added to extracted } \\
\text { groundwater resulting in a } \\
\text { concentration of } 100 \mathrm{mg} \\
\text { Sudan } \mathrm{IV} / \mathrm{L} \text { of groundwater }\end{array}$ \\
\hline Pumping Rates & $\begin{array}{l}\text { Injection } \\
\text { Extraction }\end{array}$ & $\begin{array}{l}0.5 \text { gallons/minute } \\
0.5 \text { gallons/minute }\end{array}$ & \\
\hline
\end{tabular}


into a porous media. Figure 4.1 shows the extent of injected fluid penetration. A few key assumptions in the analysis are:

Injected fluid will not enter the gravel pack or formation until an amount equal to the free volume between the packers (i.e., dead volume) is added. The free volume in the well bore/screens will be minimized with proper equipment design. Additional fluid enters the gravel pack/formation and fills a zone equal to injection volume-dead volume $=$ well screen/pipe volume.

Thus, the following equations can be derived for the radius of influence based on assuming cylindrical infiltration:

$\mathrm{V}_{\mathrm{T}}=\mathrm{V}_{1}+\mathrm{V}_{2}$ $1 a$

$\mathrm{V}_{1}=\pi \mathrm{h} \mathrm{r}_{\mathrm{w}}{ }^{2}-\mathrm{V}_{\mathrm{e}}$ $1 \mathrm{~b}$

$\mathrm{V}_{2}=\eta \pi \mathrm{h} \mathrm{r}_{\mathrm{i}}^{2}-\eta \pi \mathrm{h} \mathrm{r}_{\mathrm{w}}^{2}$ 1c

Therefore: $V_{T}=\pi h r_{w^{2}}-V_{e}+\left(\eta \pi h r_{i}^{2}\right)-\eta \pi h r_{w^{2}}$ $2 a$ solving for $r_{i}$ :

$\mathrm{VT}=\left((1-\eta) \pi \mathrm{hr} \mathrm{w}^{2}\right)+\eta \pi \mathrm{hr} \mathrm{r}^{2}-\mathrm{Ve}_{\mathrm{e}}$

$\left(\eta \pi \mathrm{hr}_{\mathrm{i}}^{2}\right)=\mathrm{V}_{\mathrm{T}}+\mathrm{V}_{\mathrm{e}}-\left((1-\eta) \pi \mathrm{hr}_{\mathrm{w}}{ }^{2}\right)$

$r_{i}^{2}=\left(V_{T}+V_{e}-\left((1-\eta) \pi h r_{w}^{2}\right)\right) /(\eta \pi h)$

$r_{i}=\left\{\left(\left(V_{T}+V_{e}-(1-\eta) \pi h_{w}{ }^{2}\right) /(\eta \pi h)\right\}^{1 / 2}\right.$

where:

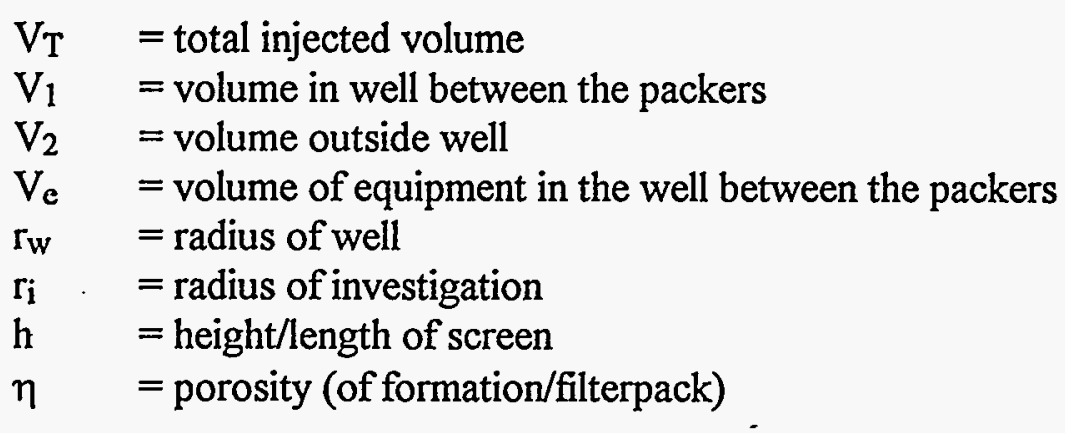

Table 5.1 and Figure 5.1 show the results of this scoping calculation and corresponding graph of the radius of infiltration as a function of injected volume for a 4 " diameter well. In 
Table 5.1 Radius of Infiltration of Injection Fluid for a 4" dia. Well as a Function of Equipment Volumes and Injection Volumes.

\begin{tabular}{|lr|}
\hline Assumptions & \\
& \\
rw $_{\mathrm{w}}$, radius of well (ft): & 0.17 \\
$\eta$, porosity: & 0.4 \\
h, length of screen/casing (ft): & 7 \\
& \\
$\mathrm{~V}_{1}, \max$ - max. dead volume $\left(\mathrm{ft}^{3}\right):$ & 0.61 \\
$\mathrm{~V}_{1}$, max (gallons): & 4.6 \\
\hline
\end{tabular}

\begin{tabular}{|c|c|c|c|c|}
\hline \multicolumn{2}{|l|}{ Table of Values } & \multirow{2}{*}{$\begin{array}{c}\text { case } 1 \\
V_{e} \\
\text { equipment volume } \\
V_{e}=3.5 \text { gallons } \\
r_{i} \text {, radius of } \\
\text { investigation } \\
\text { (ft) }\end{array}$} & \multirow{2}{*}{$\begin{array}{c}\text { case2 } \\
\mathrm{V}_{\mathrm{e}} \\
\text { equipment volume } \\
\mathrm{V}_{\mathrm{e}}=2.5 \text { gallons } \\
\mathbf{r}_{\mathrm{i}}, \text { radius of } \\
\text { investigation } \\
\text { (ft) }\end{array}$} & \multirow{2}{*}{$\begin{array}{c}\text { case } 3 \\
\mathrm{~V}_{\mathrm{e}} \\
\text { equipment volume } \\
\mathrm{V}_{\mathrm{e}}=1.5 \text { gallons } \\
\mathrm{r}_{\mathrm{i}}, \text { radius of } \\
\text { investigation } \\
\text { (ft) }\end{array}$} \\
\hline $\begin{array}{c}V_{t} \\
\text { injection volume } \\
\left(\mathrm{ft}^{3}\right)\end{array}$ & $\begin{array}{c}V_{t}^{\prime} \\
\begin{array}{c}\text { injection volume } \\
\text { (gallons) }\end{array} \\
\end{array}$ & & & \\
\hline 0.67 & 5 & 0.29 & आ 027 & 0.24 \\
\hline 1.34 & 10 & 0.40 & 0.38 & 0.36 \\
\hline 2.01 & 15 & 0.49 & 0.47 & 0.46 \\
\hline 2.67 & 20 & 0.56 & 0.55 & 0.53 \\
\hline 3.34 & 25 & 0.62 & 0.61 & 0.60 \\
\hline 4.01 & 30 & 0.68 & 0.67 & 0.66 \\
\hline 4.68 & 35 & 0.74 & 0.73 & 0.72 \\
\hline 5.35 & 40 & 0.79 & 0.78 & 0.77 \\
\hline 6.02 & 45 & 0.83 & 0.82 & 0.81 \\
\hline 6.68 & 50 & 0.88 & 0.87 & 0.86 \\
\hline 7.35 & 55 & 0.92 & 0.91 & 0.90 \\
\hline 8.02 & 60 & 0.96 & 0.95 & 0.94 \\
\hline 8.69 & 65 & 1.00 & 0.99 & 0.98 \\
\hline 9.36 & 70 & 1.04 & 1.03 & 1.02 \\
\hline 10.03 & 75 & 1.07 & 1.07 & 1.06 \\
\hline 10.70 & 80 & 1.11 & 1.10 & 1.09 \\
\hline 11.36 & 85 & 1.14 & 1.13 & 1.13 \\
\hline 12.03 & 90 & 1.17 & 1.17 & 1.16 \\
\hline 12.70 & 95 & 1.21 & 1.20 & 1.19 \\
\hline 13.37 & 100 & 1.24 & 1.23 & 1.22 \\
\hline
\end{tabular}

Note: Shaded areas in table represent radii that are less than the radius of the borehole. 


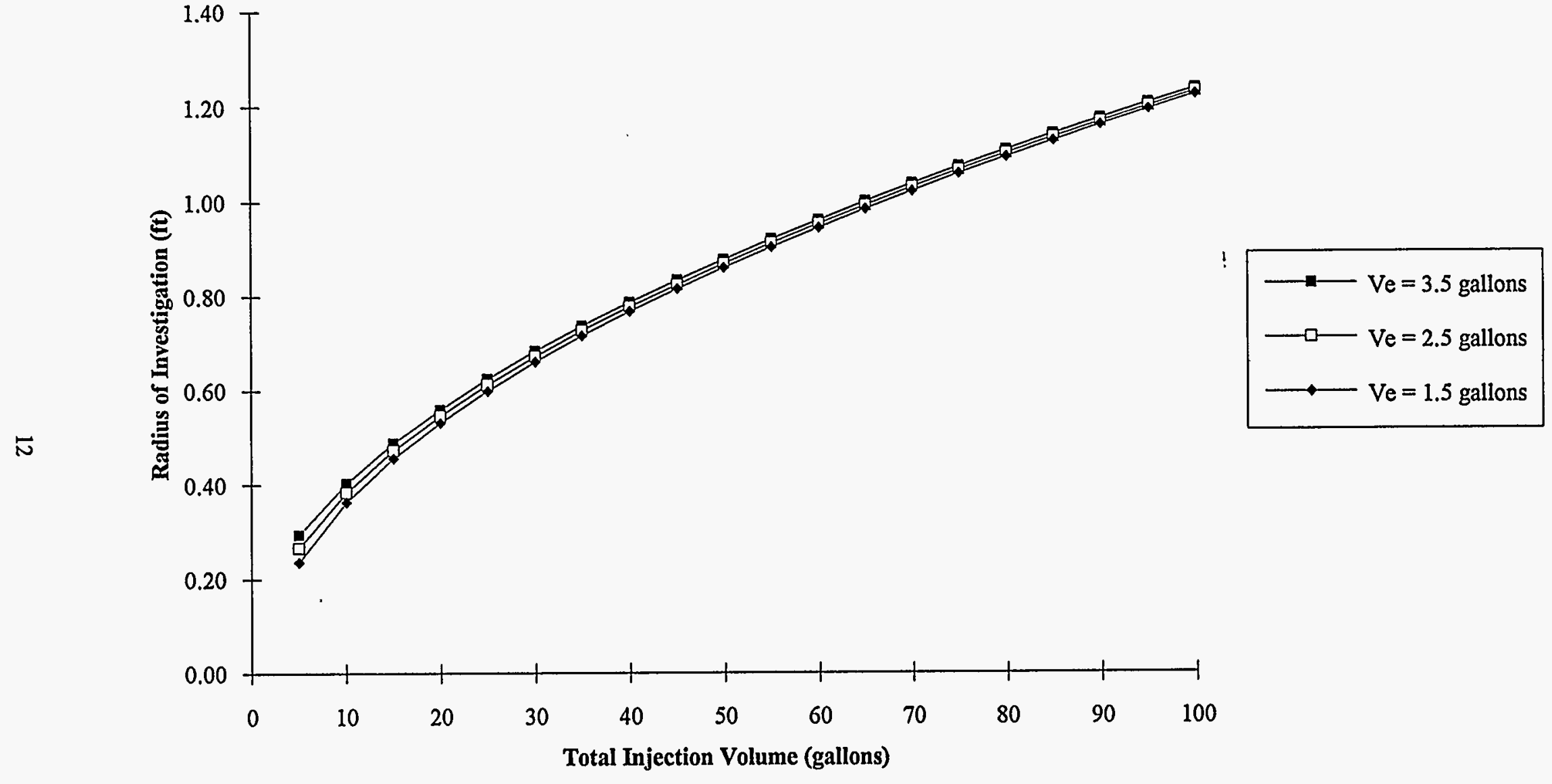

Figure 5.1 Radius of Infiltration of Injection Fluid for a 4" dia. Well

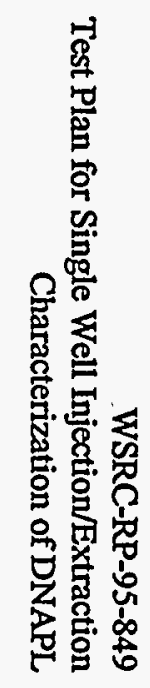


selecting the volume of injection fluid, the radius of investigation must be greater than the radius of the borehole. Monitoring wells in A/M-Area are installed in a nominal 8" borehole, thus, the radius of investigation must be greater than four inches. A penetration of $4-7$ inches (i.e., $0.67 \mathrm{ft} \leq r_{i} \leq 0.92 \mathrm{ft}$ ) into the natural formation was selected for purposes of this test. An injection volume of approximately 50 gallons will meet the goals of penetration into the natural formation. As shown on Figure 5.1, moderate injection volume increases above this value will not substantially increase the volume tested. Thus, we will limit the injection volume to 50 gallons for each test. The extraction volume proposed is approximately three times the injection volume to flush amendments from the test zone. Table 4.1 gives parameters for the alcohol injection/extraction test.

\subsection{Selection of Solubilizing Alcohol}

There are two primary mechanisms of DNAPL characterization/recovery by alcohol flooding: 1) solubilization by increasing DNAPL carrying capacity of the water phase and 2) mobilization through interfacial tension (IFT) reduction and DNAPL swelling. Low molecular weight alcohols (e.g. methanol, ethanol or isopropanol) tend to stay in the water and solubilize DNAPL. Larger alcohols (e.g. tert-butyl alcohol) tend to dissolve in DNAPL; swelling the DNAPL and changing the IFT, resulting in bulk mobilization. High efficiency (rapid removal) can be achieved by mobilization. While theoretically effective, mobilization entails some risk of undesirable gravitational movement of the mobilized phase. As a result, solubilization represents a more appropriate near term characterization activity and may represent the most defensible initial remediation approach (balancing speed and risk). Effects of IFT reduction, solubilization, and swelling are described using a ternary phase diagram; providing a useful tool in choosing an alcohol for testing.

Ternary phase diagrams can be used to represent two-phase systems consisting of DNAPL, water, and alcohol. Diagrams for these component systems consist of an equilateral triangle with each apex representing a pure component. As shown in Figure 5.2, all possible ternary compositions fall on the interior of the triangle; the sides representing binary mixtures in which the component at the opposite apex is absent. Customarily, the alcohol is placed at the top of the diagram, water on the left apex and DNAPL phase on the right apex.

Within the ternary diagram, a solubility or binodal curve separates regions of one phase (homogeneous solutions) and two phases (solutions with two parts). Above the solubility curve, all components are present in a single phase. Any overall composition falling within the two-phase region actually is a mixture of two insoluble, saturated liquid phases of equilibrium compositions---the compositions of aqueous (water rich) and DNAPL (DNAPL rich) phases. These compositions are represented by endpoints of the tie line that passes through the overall composition point. In Figure 5.2, endpoints $x$ and $y$ of the tie line passing through point $B$ give compositions of the aqueous and DNAPL phases, respectively, for the overall composition B. Point B is a mixture of $52 \%$ alcohol, $10 \%$ DNAPL and $38 \%$ water. The aqueous phase, represented by point $x$, is composed 


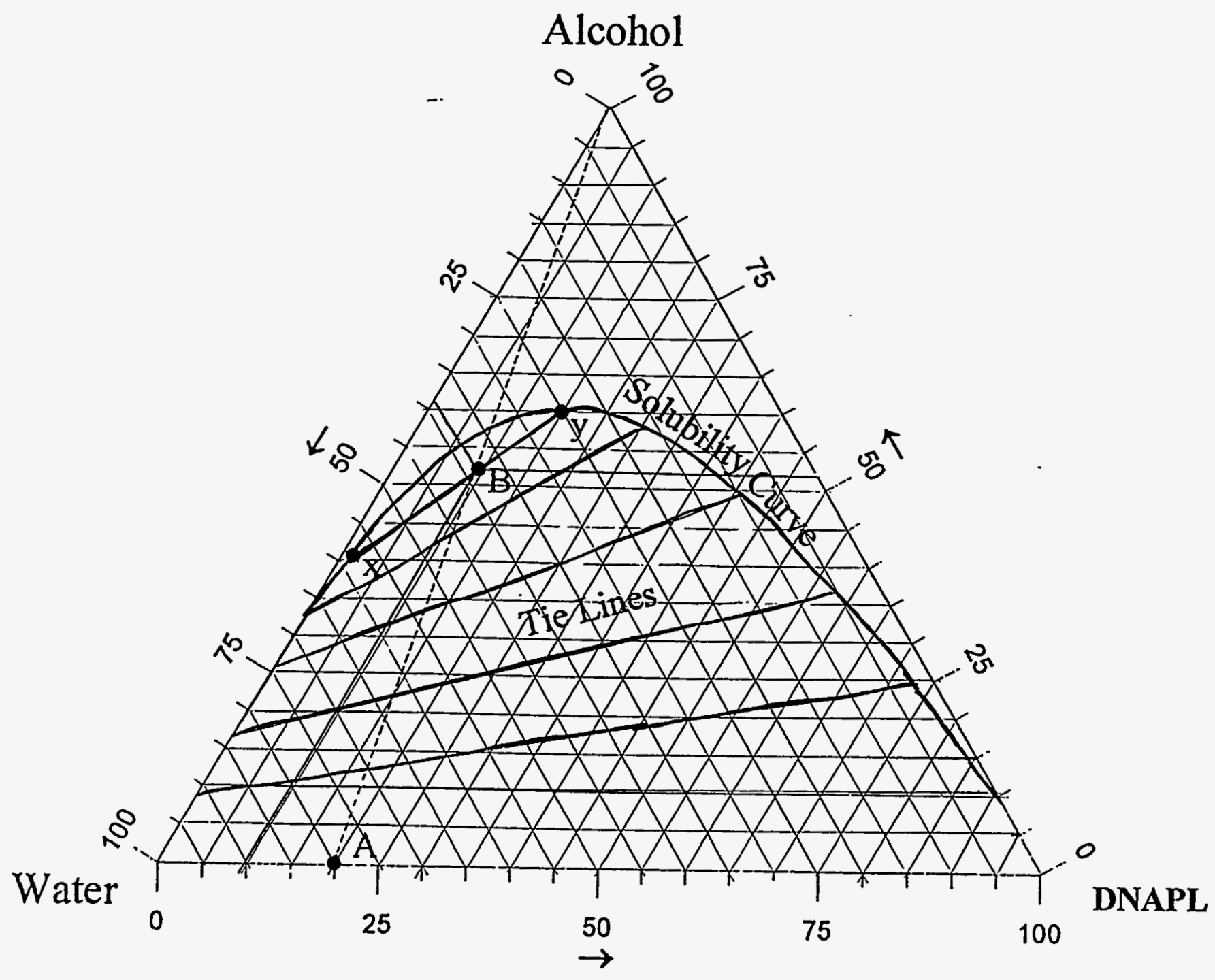

Figure 5.2 Ternary Phase Diagram for Alcohol-Water-DNAPL System 
of $41 \%$ alcohol, $1 \%$ DNAPL and $58 \%$ water. The DNAPL phase, represented by point $y$, is composed of $60 \%$ alcohol, $15 \%$ DNAPL and $25 \%$ water. Because the endpoints define the equilibrium compositions of aqueous and DNAPL phases, the tie lines also represent lines of constant IFT (IFT is reduced as more alcohol is added to the system).

For low moleular weight alcohols, such as isopropanol, there is a strong affinity to remain in the aqueous phase and solubility of DNAPL is enhanced in the alcohol-rich aqueous phase. In this case, the ternary phase diagram has a negative slope of the tie lines. Here the DNAPL phase is diminished through dissolution as alcohol concentration increases.

Interfacial tension between the aqueous and DNAPL phase can be decreased by increasing alcohol concentrations in the two-phase region. This reduction causes elongation of trapped DNAPL globules; making them easier to displace through pore constrictions.

Swelling occurs when the alcohol preferentially partitions into the DNAPL phase rather than into the water. In general, higher molecular weight alcohols are less polar and tend to preferentially partition into the DNAPL phase. Such a system is characterized by a ternary phase diagram with the lines having a positive slope.

Ternary phase diagrams illustrate the dramatic differences in phase behavior possible with different alcohols at varying concentrations. For our proposed test, we are emphasizing solubilization as opposed to mobilization. Based on this criteria, methanol, ethanol and isopropanol were evaluated for use as the solubilizing alcohol. A review of solubilization versus mobilization, as discussed in the next section, combined with a review of toxicity of these alcohols led to selection of ethanol as the solubilizing alcohol.

The focus of the tests will be on injection of very small amounts (at flows in the gallons per hour range) of ethanol solution which will increase solubility. This approach maximizes extraction with minimal bulk mobilization (interfacial tension) change, limiting the potential for downward migration of mobilized DNAPL during characterization. Solubilization will meet our characterization objectives and provide useful information about behavior of solutions in the formations.

\subsection{Selection of Solubilizing Alcohol Concentration}

Two factors were evaluated against each other to determine the concentration of the solubilizing alcohol for the injection/extraction tests. Solubility and interfacial tension were evaluated as a function of cosolvent concentration. Results of a study conducted by Hayden, etal.(1995) investigating removal of DNAPL mixtures from water-saturated aquifer materials using methanol and ethanol for cosolvent flushing were useful in determining the ethanol concentration to be used in the proposed tests.

The goal is to select a concentration of alcohol which will give a significant/defendable change in concentration over the control (water with no alcohol) stage of the test and will 
not decrease interfacial tension to a level where DNAPL becomes mobile. Figure 5.3 presents a comparison of $\mathrm{PCE}$ solubility as a function of varying concentrations of isopropanol, ethanol, and methanol. Figure 5.4 presents a comparison of PCE interfacial tension as a function of varying concentrations of isopropanol, ethanol, and methanol. Isopropanol and methanol results for both figures are based on laboratory data. Ethanol results were derived by interpolation of the isopropanol and methanol data. A factor of two, at a minimum, was determined to be a defendable concentration change from the alcohol stage test over the water only stage test. A $20 \%$ by volume of ethanol is required to achieve this. By increasing the volume of ethanol to $25 \%$ a three fold increase over the water only case is achieved. Interfacial tension at these two concentrations is approximately 20 and 16 dynes $/ \mathrm{cm}$, respectively. Both are well above the 5 dynes $/ \mathrm{cm}$ interfacial tension selected as the cutoff for acceptable interfacial tension.

Based on review of the data, a $25 \%$ by volume ethanol concentration has been selected for the injection/extraction tests.

\subsection{Selection of Wells}

A list of "DNAPL suspect wells" was identified in the Phase I DNAPL Characterization (WSRC, 1992). All wells with concentrations greater than $20 \mathrm{ppm}$ (10\% of the solubility of PCE) were selected for physical and chemical examination. Of these wells, DNAPL was confirmed in only two wells. The injection/extraction test will be used to test a subset of DNAPL suspect wells for explicit confirmation or rejection of the presence of DNAPL. The original list of DNAPL suspect wells was: MSB2C, MSB3D, MSB9B, MSB9C, MSB10C, MSB11C, MSB11F, MSB15D, MSB22, MSB23, MSB23B, MSB24A, MSB27A, MSB31B, MSB31C, MSB34B, MSB40B, MSB41D, RWM1, RWM2, RWM3, RWM6, and RWM10.

The subset of wells to be used to demonstrate the injection/extraction characterization include confirmed DNAPL wells (2), DNAPL suspect wells whose actual status is unknown (3), and a control well (1). Confirmed DNAPL wells to be tested are MSB3D and MSB22. Visual and chemical analysis of previous bailer samples confirm the presence of DNAPL in the vicinity of these wells. Unconfirmed DNAPL suspect wells to be tested are MSB9C, MSB11F, and MSB15D. These wells are near wells MSB3D and MSB22, and are generally similar in construction and geology.

A control well, MHT9D, will also be tested. MHT9D is in the same vicinity and geology as the other wells. Because of its position, however, concentrations are significantly lower than the suspect wells.

It is not feasible to test all of the suspect wells at SRS as part of the technology demonstration activities. The planned activity, however, may allow better determination about the potential for DNAPL in the remaining suspect well list. Also, if the test proves successful (a rapid economical means to explicitly identify DNAPL), remaining 


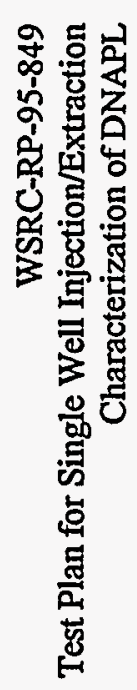

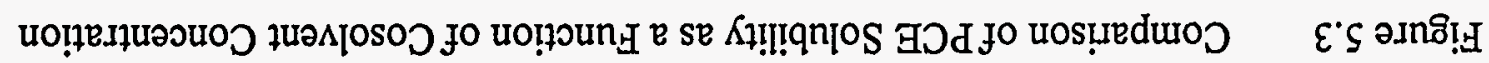
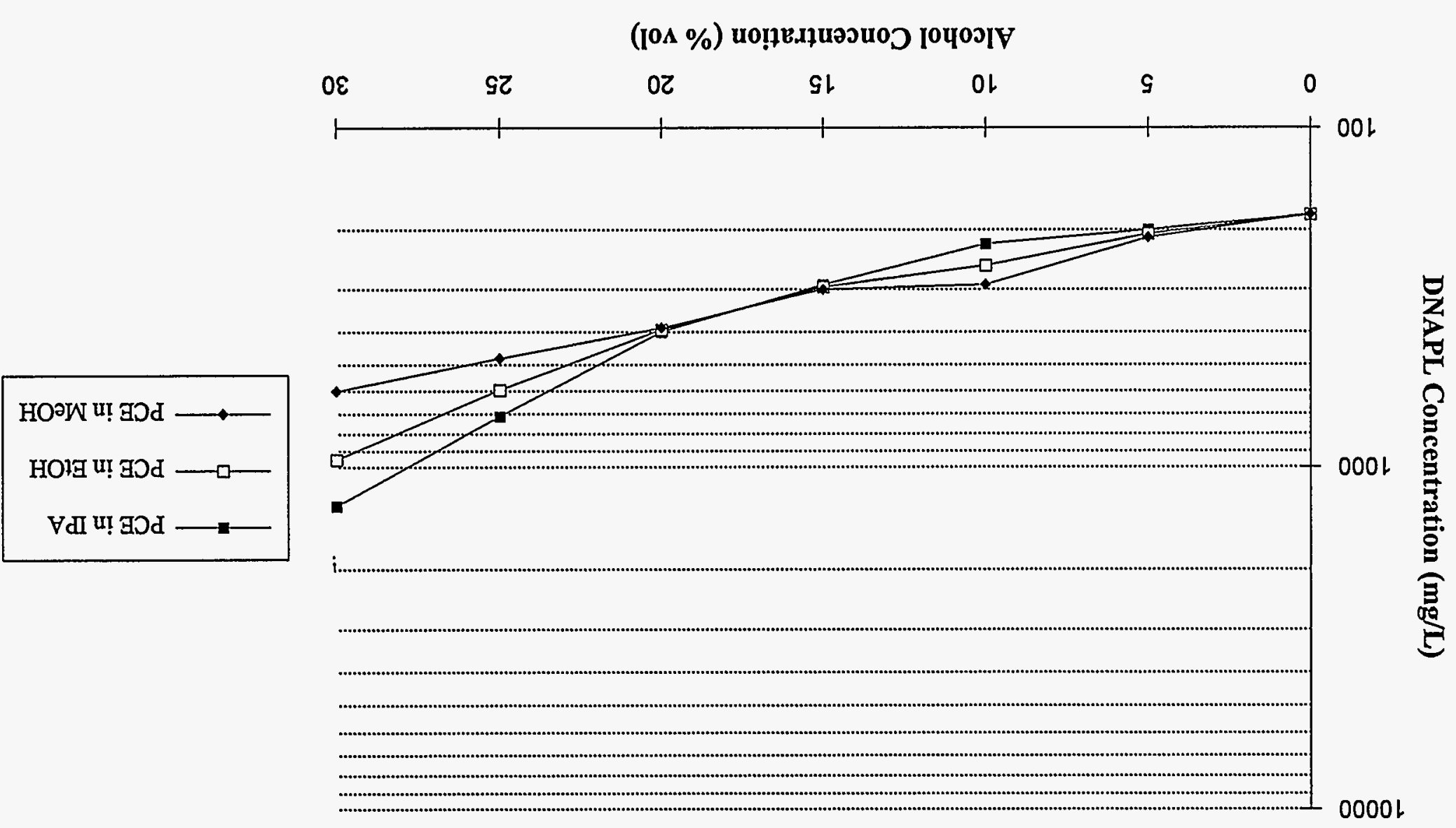


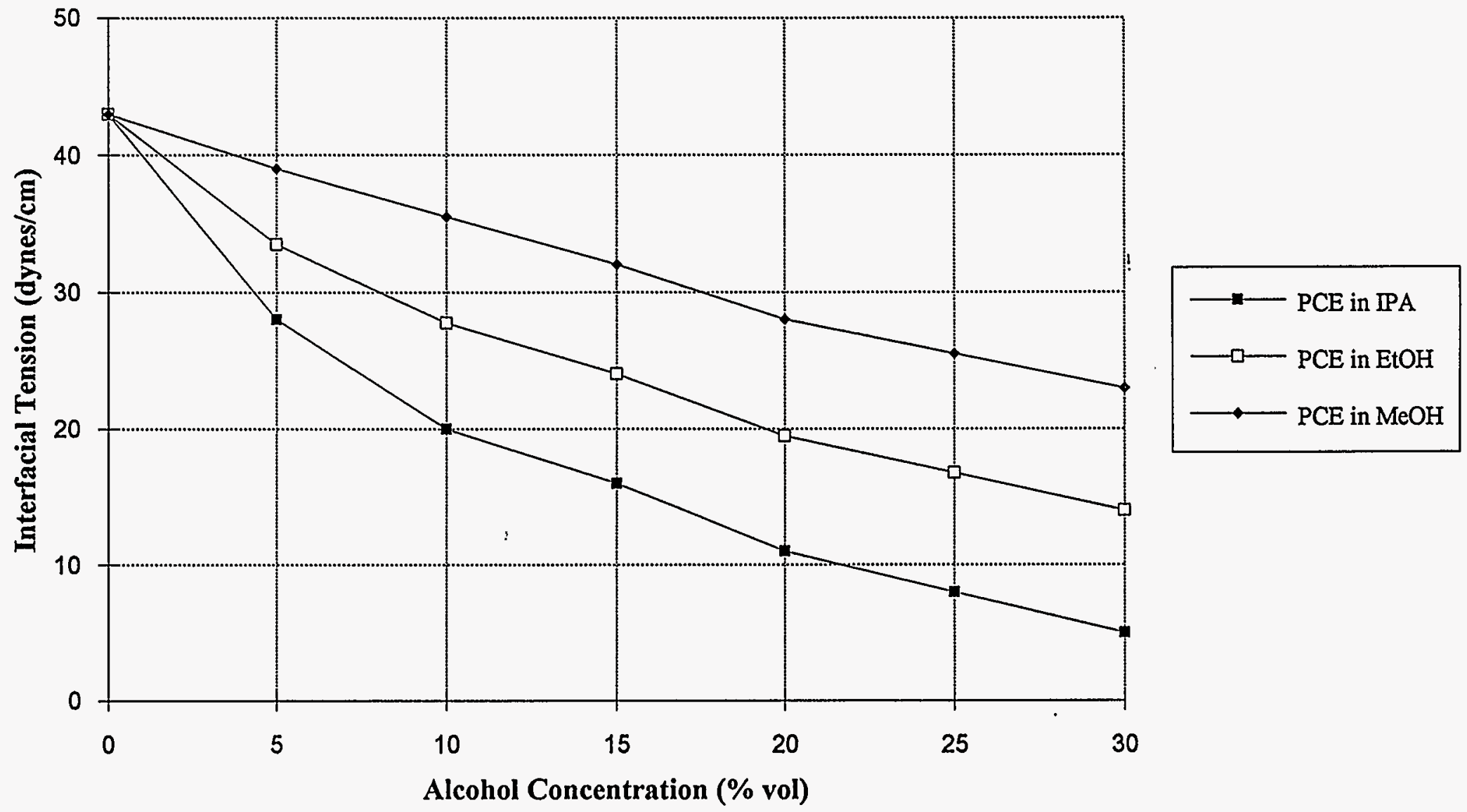

Figure 5.4 DNAPL Interfacial Tension as a Function of Alcohol Concentration

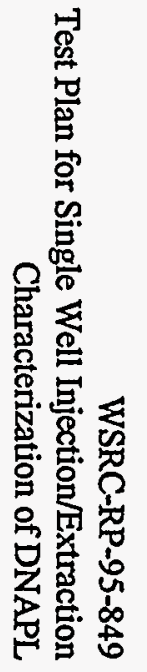


DNAPL) suspect wells could be tested through the Environmental Restoration Program using the protocols developed.

\subsection{Selection of Tracers}

Effectiveness of hydraulic control and documentation of efficiency of recovering injected fluids during the extraction phase of the characterization test will be based on tracers. Two tracers have been chosen for the injection/extraction test: bromide and Sudan IV. Bromide is an ionic compound commonly employed as a groundwater tracer. One advantage of using bromide as a tracer is that it will not decompose and thus will not be lost from the system. Detection and analysis of bromide can be accomplished by methods such as electrical conductance, specific ion electrode, neutron activitation analysis, liquid chromatography and ion chromatography. Sudan IV is a nonvolatile hyrophobic dye that dyes organic fluids red upon contact, but is practically insoluble in water at ambient temperatures. It has been widely used to colorize NAPL flow experiments as reported by Schwille (1988).

\subsection{Tracer Tests}

A reference inorganic water tracer (bromide), along with alcohol in the extended fluid will be used to document the fluid mass balance, assuring hydraulic control. Additionally, Sudan IV will be used as a visual examination for presence of DNAPL. Following the first test well, a short report on the mass balance closure will be submitted to the UIC staff at SCDHEC prior to performing additional tests. This report will take the form of a letter describing the test, status, and technical data evaluation as described below.

Bromide will be added to the injection fluid at a concentration of $100 \mathrm{mg} / \mathrm{L}$, and the alcohol used for solubilization will also serve as the organic tracer. We will evaluate data on both bromide and alcohol using a graph of the form shown in Figure 5.5. In this analysis, cumulative addition/extraction of tracer (in grams) is plotted vs time.

Each point on the graph is calculated using the simplified formula:

$$
m_{(t)}=m_{(t-\Delta t)}+(\Delta t)(Q)\left(C_{(t-\Delta t)}\right) / 1000
$$

where:

$\mathrm{m}_{(\mathrm{i})}=$ cumulative tracer in system at time $\mathrm{i}(\mathrm{g})$

$\mathrm{t}=$ time $(\mathrm{min})$

$\mathrm{Q}=$ flow (injection is positive, extraction is negative) $(\mathrm{L} / \mathrm{min})$

$\mathrm{C}=$ concentration of tracer in injection or extraction fluid $(\mathrm{mg} / \mathrm{L})$ 


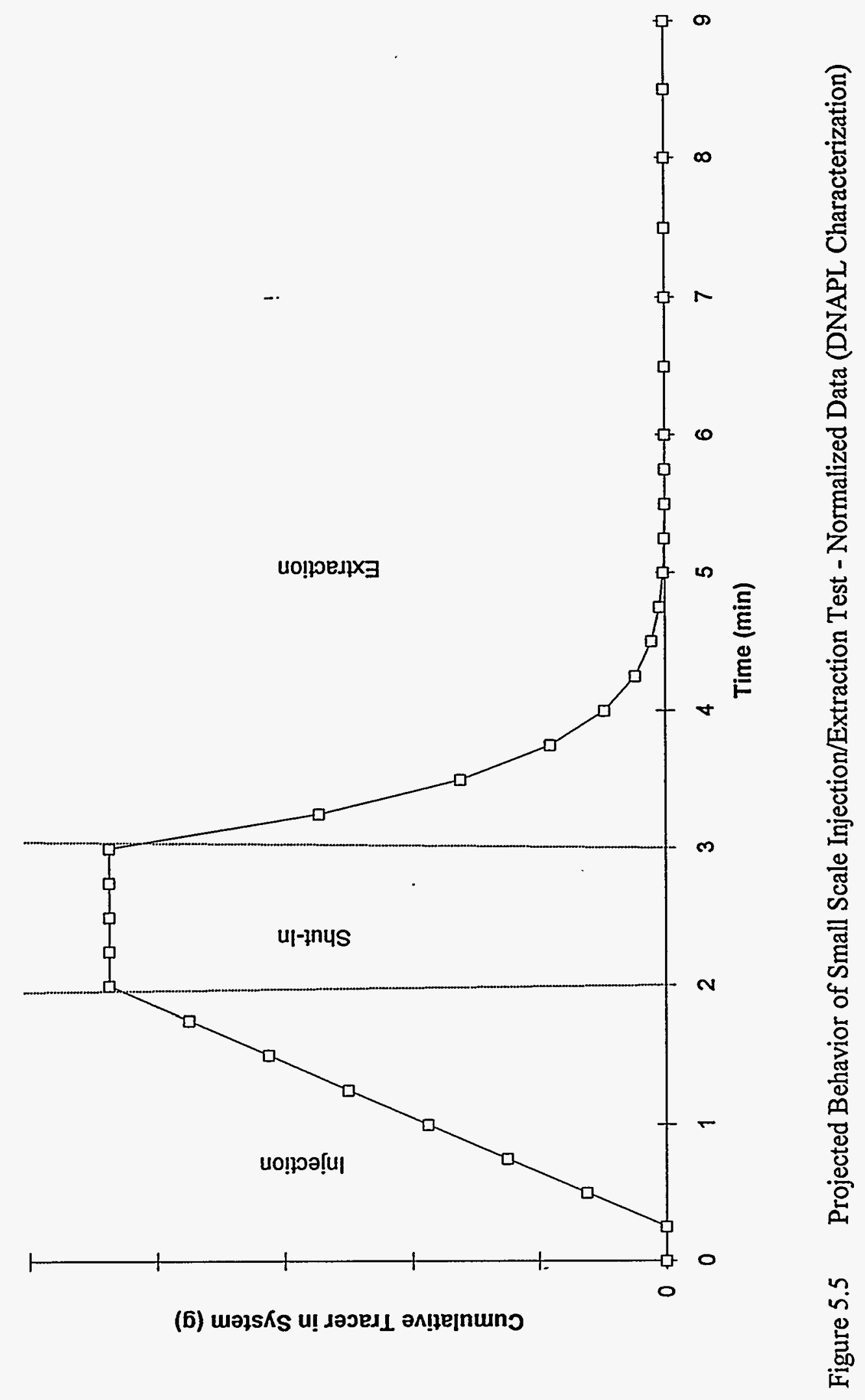


As shown in Figure 5.5, the graph will show three clear operational periods: first, the injection period in which $\mathrm{m}$ will increase linearly: second, a shut in period during which $\mathrm{m}$ is constant; and third, an extraction period during which the tracer is removed. Effective hydraulic control will be documented by the graph returning to approximately zero during the extraction period. We will also evaluate the differences between bromide and alcohol to determine if measurable amounts of alcohol sorbed are extracted into residual formation DNAPL within the penetration volume (i.e. are subtantive amounts of DNAPL still present in this zone after the short characterization test). We do not anticipate substantial biological degradation during the test. These experiments will be performed for each well tested.

Data from the cosolvent flushing and water stages of the test will be normalized and plotted on a graph similar to Figure 5.6. This figure, based on simple theoretical behavior shows the clear differences expected during the test.

Sudan IV will be added to the extracted groundwater after the groundwater/alcohol solution has been shut in the well and prior to it entering the treatment system. Sudan IV in the presence of DNAPL will turn red allowing a visual examination of the groundwater stream as it exits the well. Thus, a qualitative and semiquantitative evaluation of the amount of DNAPL removed (directly) by test operations.

\subsection{ANALYTICAL METHODS}

Primary, backup and QA lab methods are summarized in Table 6.1. QA samples will be a $5 \%$ split of the complete sample set and will be representative of all samples and all media.

\subsection{WASTE MANAGEMENT}

Non-aqueous phase liquids will be collected and disposed of as hazardous waste (RCRA F001 and TSCA as appropriate). Use of Sudan IV dye in the extract containment system will allow for visual identification of pure phase DNAPL. Sudan IV dye becomes red in the presence of pure phase DNAPL. Thus, pure phase DNAPL can be collected from the containment devices using bottom fitted drains. This pure phase DNAPL will be managed as TSCA waste: Samples of both pure phase DNAPL drained from the bottom drain and liquid remaining in the collection vessel will be analyzed for PCBs. Liquid remaining in the collection vessel will be pumped through a treatment system consisting of an oleofilter and carbon bed. The treatment system will commence with the existing wastewater treatment facility (air stripper) to remove the remaining TCE/PCE to permitted regulatory standards. Prior to transfer to the air stripper, the aqueous waste containing TCE/PCE from the oleofilter will be collected in a tank from which samples will be extracted for PCB analysis. Aqueous waste will then pass thru the carbon bed, be collected in a tank and samples extracted for PCB analysis. PCB levels will be monitored to ensure that PCB levels do not exceed $3 \mathrm{ppb}$ prior to entry into the air stripper. Figure 7.1 is a schematic of the effluent streams from the treatment system. 


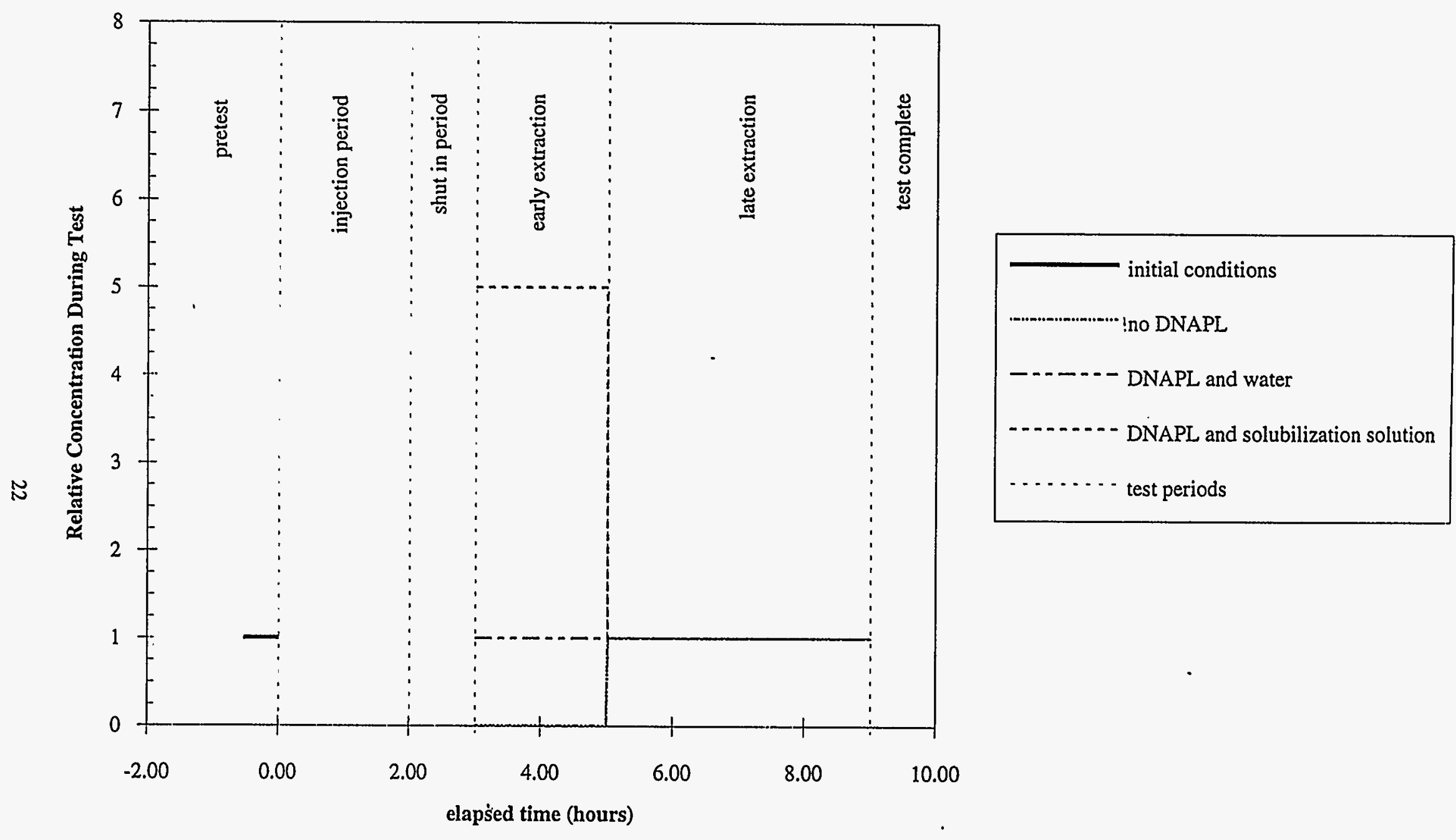

Figure 5.6 Theorteical Behavior of Small Scale Injection/Extraction Test (DNAPL Characterization)

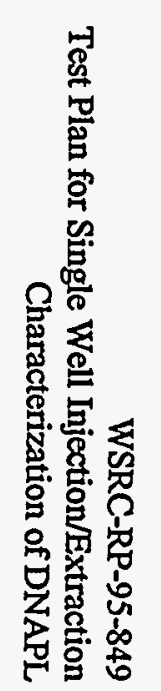


Table 6.1 Analytical Methods for the Injection/Extraction Test

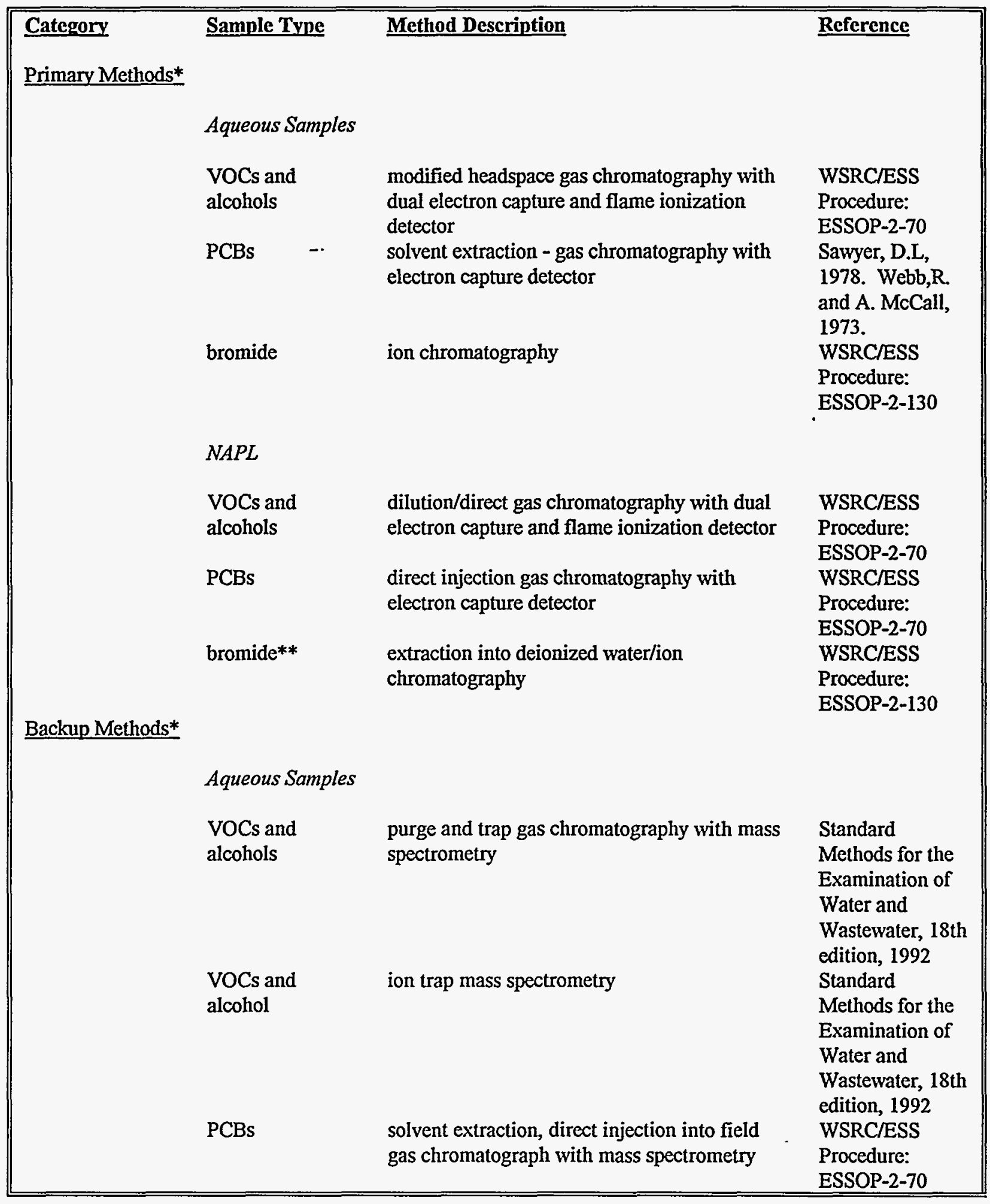


Table 6.1 Analytical Methods for the Injection/Extraction Test(continued)

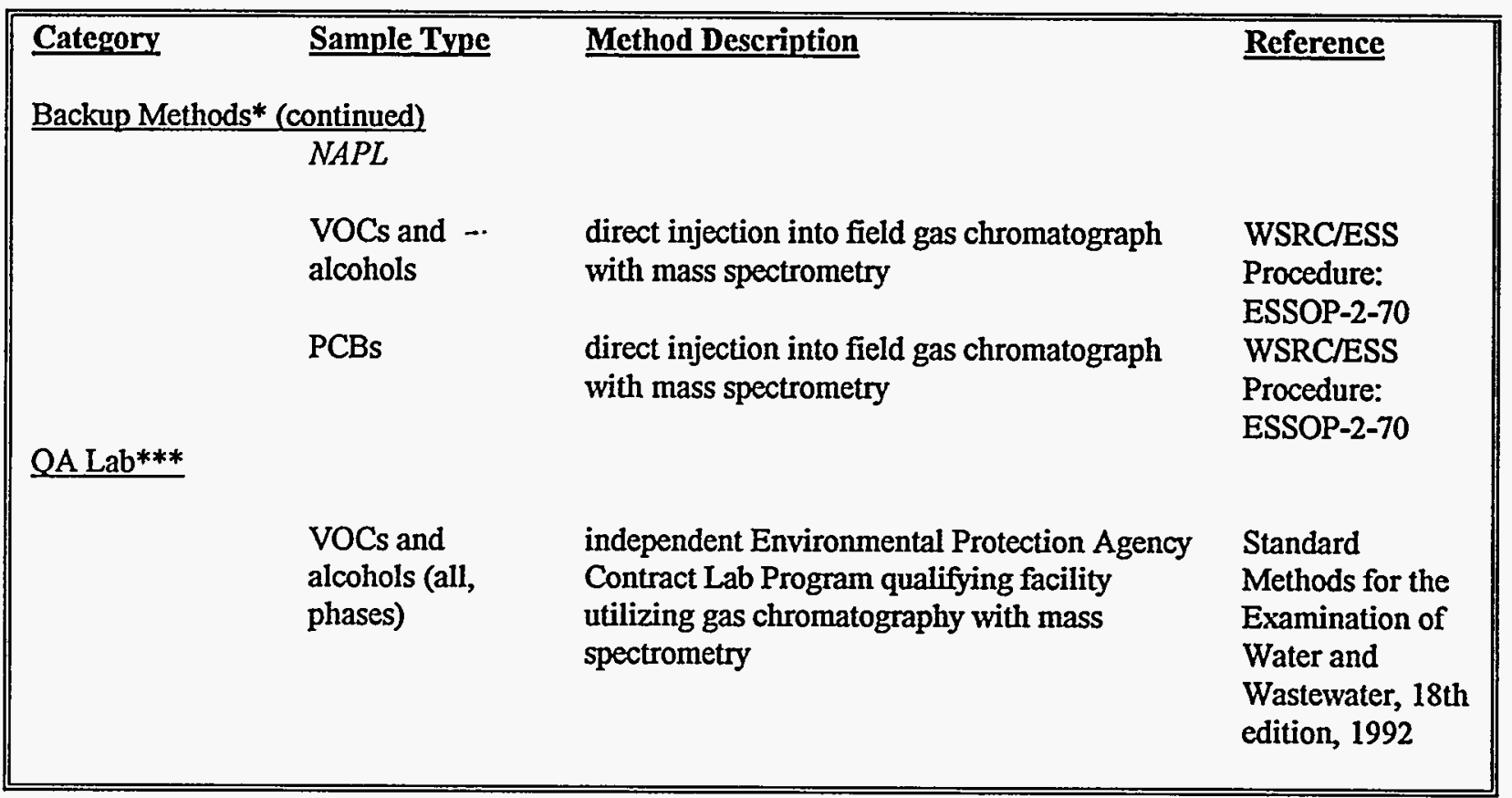

* Description of proposed methods and instrumentation. Specific configuration and conditions are described in the references.

** This will be discontinued after the first well if bromide levels are low in NAPL phase.

*** Replicate samples (approximately 5\%) will be submitted for QA. 


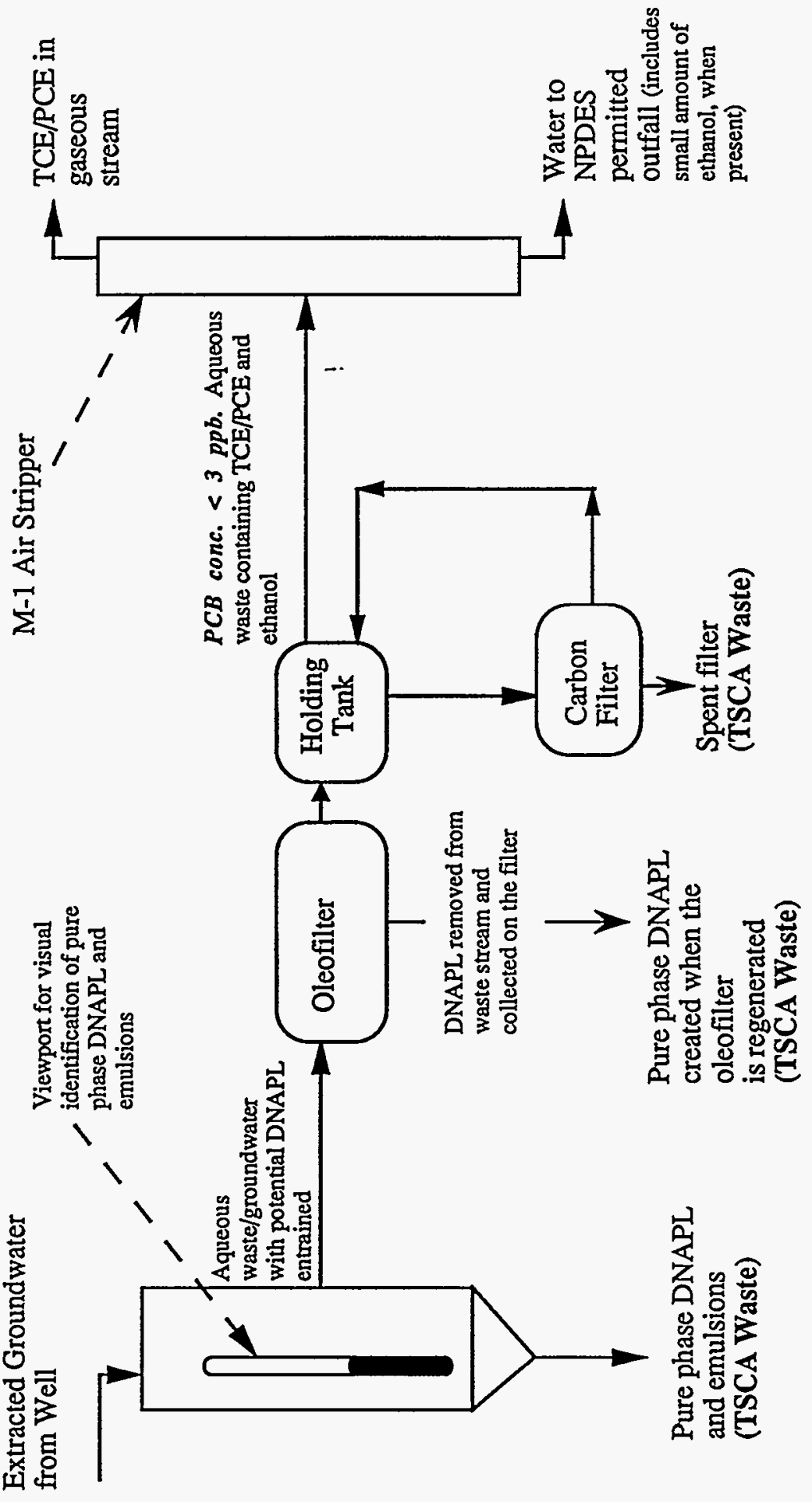

Figure 7.1 Schematic Diagram of Effluent Streams from Treatment Unit for the Well Water from the Injection/Extraction Test 
For purposes of TSCA, all visible DNAPL and emulsions of DNAPL and water will be collected and handled as TSCA waste. DNAPL will be placed in TSCA approved containers and transferred to Waste Management for disposal. To minimize waste generation, the program has a policy of reusing equipment that has contacted DNAPL (if possible) rather than discarding it as TSCA or hazardous waste. Plans for marking and storing this equipment are described below ("Process Design"). Site contacts and phone numbers are listed in the "Addresses" section. Specific questions concerning experimental design or operations can be addressed to the DOE, regulatory, or technical contacts listed.

All field experiments where DNAPL will be collected from soil and groundwater will be constructed using stainless steel, or similar solvent resistant material. All connections will be made using national pipe thread (NPT) fittings or swagelock fittings (or equal). Tanks will be monitored continuously during collection and will be fitted with sight glasses to allow direct monitoring of the collection of total fluid and DNAPL. Vessels will be fitted with bottom drains to allow collection of DNAPL. Protective containment pans and required personal protective equipment will be used for the transfers.

The injection/extraction test has a maximum target of no more than one drum (50 gallons) of liquid TSCA waste at any time. If this target is reached, injection/extraction test activities generating waste will be discontinued until the waste is accepted by Waste Management for storage and handling as SRS. Following acceptance of the waste by Waste Management into the full permitted site TSCA program, injection/extraction test activities generating waste will be allowed to continue. Over the entire planned period of operation less than 500 gallons of TSCA waste are anticipated from all injection/extraction test activities (see Attachment A). Conservatively assuming 500 gallons are generated with a concentration of $100 \mathrm{ppm}$ PCB, this is equivalent to approximately $190 \mathrm{~g}$ of PCBs (see Attachment B).

Aliquots of samples for the laboratory will be transferred in glass containers and secondary containment packaging. In the laboratory, subsampling, handling, analysis preparation and related activities will be performed in a laboratory hood with no drain (or with a sealed drain).

Solid waste generated (disposable glassware, wipes, gloves, etc.) will be collected in a TSCA approved container located near the field area. Because of the waste minimization described below, we plan to generate less than one drum of solid waste over the entire test period. A central objective of the SRS DNAPL program is minimization of secondary waste. Therefore, whenever possible, solid materials will be reused rather than discarded. Items such as sample bailers, plastic sheeting, and similar items will be placed in a sealed storage container on site. Current plans for the container are as follows: primary material for construction is flush threaded large diameter (approximately 12 ") well casing approximately 20 feet long. Ends of the pipe will be sealed with flush threaded caps. This design will allow storage of pumps, riser pipes and other materials out of monitoring wells 
that have DNAPL in the water column. Smaller items (e.g., sampling gear) will also be placed near the ends of the container for access and use. Only items that have not directly contacted DNAPL or have been cleaned (steam cleaned or solvent rinsed) will be placed in the project storage/reuse container. Steam cleaning fluids and solvent rinses will be collected and disposed as TSCA waste or RCRA IDW, as appropriate. The container in the field will be clearly labeled:

DNAPL R\&D Program Sampling and Support Equipment

TSCA suspect material, may have contacted PCBs

Contact: \{principal investigator name and phone number

for authorization to access equipment

The storage and reuse container will be elevated off the ground to protect from mowers and placed in an area protected from vehicular traffic.

\subsection{Contingency Plans}

Containment of equipment and waste, combined with use of high quality stainless steel and solvent resistant materials will control/minimize the chance of spills or unplanned releases. However, a supply of appropriate sorbent pigs and pillows will be maintained at the site to be used for rapid containment in the event of such a release. Further, SRS has a trained spill response team that will be immediately called in the event of any release of DNAPL material to the environment. Site emergency numbers are a required element of the training necessary to work at SRS. These numbers will also be posted near phones at the support facility located at the field test area adjacent to the former M Area Settling Basin. Unplanned spills or releases are rapidly reported to DOE through a formal notification system. DOE and site liaison personnel then report to appropriate regulatory agencies. All work associated with DNAPL fluids will require gloves, safety glasses and other personal protective equipment (e.g., respirators) as necessary. No eating, drinking or smoking is allowed on sampling sites or in support laboratories.

\subsection{ENVIRONMENTAL IMPACT}

No adverse environmental impact is anticipated. The research is focused on developing improved (faster and less expensive) clean up of the primary contaminants in A/M Area, TCE and PCE. A National Environmental Protection Act (NEPA), 10 CFR 1021, checklist has been completed for this activity. We anticipate a finding of insignificant impacts since the activity is covered under the following categories of exclusions: B3.1 (site characterization and monitoring), B3.8 (outdoor ecological/environmental research in a small area), and B6.2 (siting/construction/operation of pilot scale waste collection/treatment/stabilization/containment facilities). 


\subsection{ADDRESSES}

Any additional information needed related to this program may be obtained by contacting the following individuals:

Nancy Lowry, TSCA Coordinator

Westinghouse Savannah River Company

Environmental Protection Department

P.O. Box 616

Bldg. 742-A

Aiken, SC 29808

(803)-725-7305

Technical personnel and principal investigator responsible for the program is:

Brian Looney

Westinghouse Savannah River Company

Savannah River Technology Center

P.O. Box 616

Bldg. 773-42A

Aiken, SC 29808

(803) $-725-3692$

\subsection{REFERENCES}

Hayden, N.J and G. Noyes. Removal of DNAPL Mixtures from Water-Saturated Aquifer Material Using Cosolvent Flushing, Final Report, Dept. of Civil and Environmental Engineering, Univ. of Vermont (1995).

Sawyer, D. L. Quantitation of PCB residues by electron capture gas-liquid chromatography: Reference material characterization and preliminary study. J. Assoc. Off. Anal. Chem. 61:272-281 (1978).

Schwille, F. Dense Chlorinated Solvents in Porous and Fractured Media, Lewis Publishers, Chclsea, Michigan, 146 pp. (1988).

Standard Methods for the Examination of Water and Wastewater, 18th edition, 1992.

Webb, R. and A. McCall. Qunatitative PCB Standards for electron capture gas chromatography. J. Chrom. Sci. 11:366-373 (1973).

Westinghouse Savannah River Company. Assessing DNAPL contamination, AM-Area, Savannah River Site: Phase I Results $(U)$. Prepared for the US DOE Contract \#DEAC09-89SR18035 (1992). 
Attachment A

\section{Estimate of Volume of TSCA Waste Generated}

Two wells will have pure product (DNAPL) [based on available data]. For estimation purposes for the test, it will be assumed that all wells will have pure product.

6 wells will be tested. Two tests will be conducted from each well. $10 \%$ of the total volume extracted will be pure product (DNAPL) [This number is conservative.]

$5 \%$ of the total volume extracted will be a DNAPL/water emulsion.

150 gallons of liquid will be pumped from each well.

$$
\begin{aligned}
& \frac{150 \text { gallons of liquid }}{\text { test }} \underset{*}{\frac{2 \text { tests }}{\text { well }}} * 6 \text { wells }=1800 \text { gallons of liquid } \\
& 1800 \text { gallons of liquid } \quad \frac{0.1 \text { gallons of DNAPL }}{1.0 \text { gallon of liquid }}=180 \text { gallons of DNAPL } \\
& 1800 \text { gallons of liquid } \quad \underline{0.05 \text { gallons of emulsion }}=90 \text { gallons of emulsion } \\
& 1.0 \text { gallon of liquid }
\end{aligned}
$$

Total volume of TSCA waste extracted from wells prior to entry into treatment system $=270$ gallons

TSCA waste created from the oleofilter is liquid from regeneration of the filter material. The system is designed to circulate the liquid regenerant back through the oleofilter. Thus, minimizing the amount of liquid requiring disposal. It will be assumed that $10 \%$ of the incoming fluid (1530 gallons) and 600 gallons (50 gallons/test * 12 tests) of rinsewater introduced into the system through the life of the test program will be TSCA waste generated from the oleofilter.

$$
\begin{gathered}
(1530 \text { gallons }+600 \text { gallons }) * 0.1= \\
\text { oleofilter }
\end{gathered}
$$

Estimated Total Volume of TSCA Waste (Liquid) for the Test Program $=483$ gallons 


\begin{abstract}
Attachment B
Calculation of Amount of PCBs Present in 500 gallons of TSCA Waste (DNAPL containing PCBs)
\end{abstract}

Assume all of this material is $100 \mathrm{ppm}$ PCB

500 gallons of DNAPL $\frac{1000 \text { liters }}{264.17 \text { gallons }}=1890$ liters of DNAPL

1890 liters DNAPL $* \frac{100 \text { parts PCB }}{1000000 \text { parts DNAPL }} * \frac{1000 \mathrm{gm} \text { DNAPL }}{1 \mathrm{~kg} \mathrm{DNAPL}} * \frac{1 \mathrm{~kg} \text { DNAPL }}{1 \text { liter DNAPL }}$ $=189$ grams of PCB 